\title{
RE-BRANDING IDENTITAS LOGO ABIDAUFA
}

\author{
Ivo Ramadhani ${ }^{1}$, Febri Yulika $^{2}$, Syafwandi $^{3}$ \\ 1,2Program Studi Pascasarjana Institut Seni Indonesia Padang Panjang \\ ${ }^{3}$ Program Studi Antropologi Budaya, Fakultas Bahasa dan Seni Universitas Negeri Padang \\ 1ivor205@gmail.com, ${ }^{2}$ febri.isipp@ gmail.com, ${ }^{3}$ syafwandi1960@gmail.com
}

\begin{abstract}
ABSTRAK
Artikel ini membahas perancangan kembali desain branding identitas desain logo Abidaufa. Peran branding dan desain dalam proses pembentukan identitas/citra. Disebabkan makin meningkatnya kompetisi antar produsen. Abidaufa adalah sebuah brand nama dari industri rumahan bergerak dibidang fashion kulit, yang berada di jalan Amal (Jl. Puskesmas) MedanBinjai. Abidaufa berdiri pada bulan Oktober 2013, hingga kini telah memproduksi aneka kerajian dari kulit, berupa dompet, ikat pinggang, tas, dan tali jam tangan. Adapun bahan kulit yang diproduksi berasal dari kulit sapi, kulit ikan pari, kulit biawak dan kulit ular. Sebagai industri rumahan, Abidaufa telah berhasil menarik minat pembeli melalui hasil karya yang diproduksi. Pembeli datang tidak hanya dari daerah Kota Medan saja melainkan dari luar kota. Abidaufa telah memiliki logo, tetapi logo Abidaufa belum memiliki mewakili karakter, visi, dan misi dari usaha yang dijalankan, maka dengan itu dilakukan rebrending logo sesuai karakter yang mewakili visi dan misi dari Abidaufa. Pada perancangan logo Abidaufa, berdasarkan analisis studi literartur yang relevan memakai metode $5 \mathrm{~W}+1 \mathrm{H}$, logo menggunakan konsep warna, tipografi, dan jenis komposisi yang memberikan kesan profesional sesuai dengan visi dan misi Abidaufa.
\end{abstract}

KATA KUNCI : re-branding, logo, Abidaufa

\begin{abstract}
This article discusses the design re-design of the Abidaufa logo design logo. The role of branding and design in the process of identity / image formation. Due to increasing competition between producers. Abidaufa is a brand name of home industry engaged in leather fashion, which is located at Amal Street (Jalan Puskesmas) Medan-Binjai. Abidaufa stands in October 2013, until now has been producing various leather, in the form of wallet, belt, bag, and watch strap. The leather material is produced from cowhide, stingray skin, lizard skin and snake skin. As a home-based industry, Abidaufa has managed to attract buyers through the work produced. Buyers come not only from the city of Medan alone but from out of town. Abidaufa already has a logo, but the Abidaufa logo does not yet represent the characters, vision, and mission of the undertakings, hence rebranding the logo according to the character representing the vision and mission of Abidaufa. In the design of the Abidaufa logo, based on the analysis of the relevant literary studies using the $5 \mathrm{~W}+1 \mathrm{H}$ method, the logo uses the concept of color, typography, and type of composition that gives a professional impression in accordance with Abidaufa'svision and mission.
\end{abstract}

KEYWORDS: redesign, branding, logos, Abidaufa 


\section{PENDAHULUAN}

Sejalan dengan perkembangan zaman, begitu pula dengan perkembangan yang pesat dalam dunia bisnis. Seiring dengan itu, maka muncul banyak produk baru yang menimbulkan persaingan bisnis. Banyaknya produk sejenis yang muncul, sehingga banyak pula nama merek dan logo yang hadir, hal ini membuat persaingan produk semakin ketat dalam menarik perhatian konsumen. Merek dan logo sendiri merupakan sebuah identitas yang dibuat untuk membedakan antara satu produk dengan produk lainnya. Menurut Kusrianto dikutip oleh A.D.W. Utami, dkk., menyatakan bahwa:

"Logo atau tanda gambar (picture mark) merupakan identitas yang dipergunakan untuk menggambarkan citra dan karakter suatu lembaga atau perusahaan maupun organisasi. Logotype atau tanda kata (word mark) merupakan nama lembaga, perusahaan atau produk yang tampil dalam bentuk tulisan yang khusus untuk menggambarkan ciri khas secara komersial" (Kusrianto, 2009: 232).

Pendiri Abidaufa terdiri atas dua orang bersahabat, salah satunya seorang pengrajin dari Jogyakarta. Abidaufa adalah usaha home industri yang mengolah produk berbahan kulit. Abidaufa mendapatkan bahan kulitnya dari Kota Jogyakarta. Produk diproduksi $80 \%$ adalah kulit asli, yaitu kulit sapi, ular, biawak dan buaya. Proses pembuatan produk dapat berlangsung selama 5 (lima) sampai 6 (enam) jam dapat dilihat dari tingkat kesulitan dan permintaan konsumen. Abidaufa memproduksi dengan alat mesin seset, amplas, embos. dan mesin jahit yang memiliki kecepatan yang dapat diatur. Produk yang diproduksi oleh Abidaufa berupa tas, dompet, ikat pinggang, dan accessories berbahan kulit lainnya. Proses penjualannya selain di rumah owner penjualan juga dilakukan melalui mengikuti event-even sosial seperti pameran serta media sosial seperti BBM, Facebook, Intsagram dan media sosial lainnya. Harga produk bervariasi mulai dari 20.000 sampai 2.000.000 dan tergantung dari tingkat kesulitan dari produk yang dihasilkan.

Abidaufa telah memiliki logo, akan tetapi logo tersebut belum mewakili karakter, visi, dan misi dari usaha yang dijalankan. Karakter logo Abidaufa belum menggambarkan bahwasannya Abidaufa adalah pengolah produk berbahan kulit dan dijalankan oleh dua orang sahabat, serta belum adanya identitas warna olahan dari produknya.Padahal identitas atau ciri logo sangat penting untuk menunjang hasil yang diproduksi. Sebagaimana yang dinyatakan olehRatranto, bahwa:

Dalam suatu perusahaan, logo sangat berperan penting untuk mewakili ciri daripada produk yang diproduksi, sehingga dapat membantu dalam hal memperkenalkan usaha atau bisnis kepada konsumen. Sebuah usaha kecil yang sukses memerlukan logo yang tepat dan memerlukan pengakuan yang didapat dari sebuah logo bisnis yang baik (Ratranto, 2012: 5).

\section{STUDI LITERATUR}

Dalam penulisan makalah ini, penulis banyak melakukan studi literatur pada bukubuku, tesis, jurnal dan penelitian berkaitan tentang branding yang telah dilakukan oleh pengkarya sebelumnya. Data yang di dapat dari studi literatur ini digunakan sebagai acuan dalam membuat karya. 
1. Kriteria Logo yang Baik

Menurut Evelyn Lip (A.D.W. Utami, dkk. 2016, 56), menyatakan, bahwa desain logo atau merek dagang harus memenuhi kondisi-kondisi bawah ini:

a. Harus sesuai dengan kebudayaan.

b. Logo harus menyandang citra yang diinginkan dan menunjukkan keadaansebenarnya atau kegiatan dari perusahaan serta menggambarkan sasaran komersialorganisasinya yang diwakilinya, sedangkan merek dagang harus didesain untukmewakili produk suatu perusahaan.

c. Harus merupakan alat komunikasi visual.

d. Harus seimbang dan, karena itu, bisa dengan hitam putih atau seimbang dalamwarna.

e. Logo harus menggambarkan suatu irama dan proporsi.

f. Harus artistik, elegan, sederhana namun memiliki penekanan atau titik fokus.

g. Desainnya harus harmonis.

h. Harus menggabungkan tulisan/huruf yang tepat sehingga dapat menyampaikanpesan yang dimaksud secara logis dan jelas.

i. Harus menguntungkan secara Feng Shui dan seimbang dalam unsur yin dan yang (Lip, 1996).

2. Anatomi Logo

Menurut Surianto Rustan (2009) seperti yang dikutip oleh A.D.W. Utami, dkk.,menjelaskan bahwa "mengetahui anatomi dan jenislogo akan mempermudah dalam menentukan logo apa yang akan dibuat dan jenismana yang paling mewakili kepribadian entitasnya". Logo bisa berupa gambar,tulisan, atau gabungan antara keduanya. Anatomi logo bisa membantu memahami jenis dan elemen visual pembentuk logo. Per Mollerup menjelaskan "picture mark dan letter mark cukup memadai untuk menyebu telemen gambar dan elemen tulisan dalam sebuah logo"(Kusrianto,2016:58) berikut.

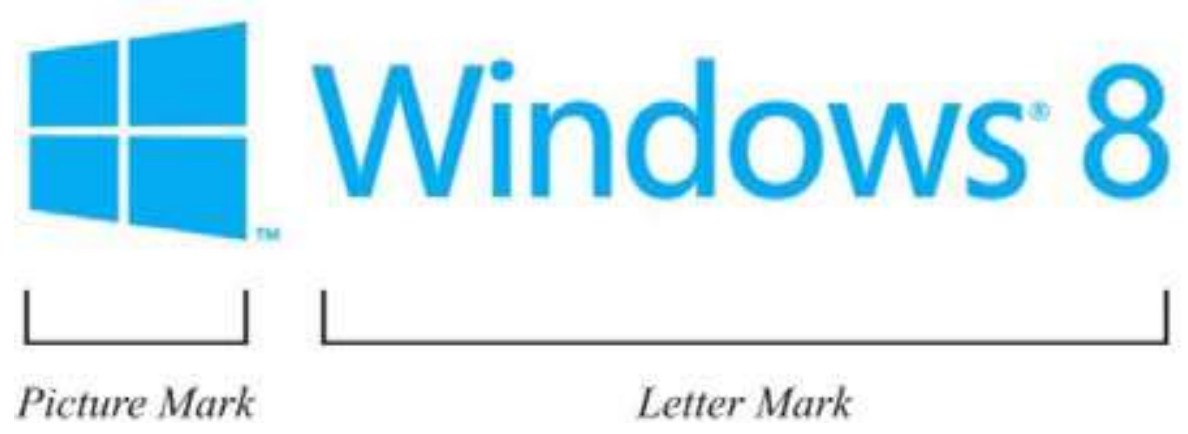

Gambar 1. Anatomi Logo (Kusrianto, 2016:59)

(Sumber : Ivo Ramadhani, 2017) 


\section{Rebranding}

K. Molekandella Boer, mengatakan bahwa: "Re-branding berasal dari kata re- dan branding.Re berarti kembali, sedangkan branding adalahproses penciptaan brand image yag diinginkanperusahaan. Re-branding adalah upaya perusahaanuntuk memperbarui sebuah brand yang telah adaagar menjadi lebih baik, namun tidak mengabaikandan melupakan tujuan awal perusahaan, yaituprofit” (K. Molekandella Boer, 2014).

K. Molekandella Boer, mengatakan merek merupakan salah satu aset organisasi yang paling berharga, karena sebagai identifikasiproduk dari perusahaa sementara bagi konsumenmerek berperan krusial sebagai identifikasi sumberproduk, penetapan tanggung jawab pada produsendan distributor spesifik, pengurangan resiko,penekan produsen, alat simbolis yang memproyeksikancitra diri dan signal kualitas. Dalam kebanyakankasus rebranding perusahaan menggantinamanya dalam rangka memfasilitasi peluanhekspansi keberbagai kategori produk atau pasargeografis baru (K. Molekandella Boer, 2014).

\section{Brand Religion}

K. Molekandella Boermengatakan brand religion adalah capaian tertinggi sebuahmerek. Levelnya masih di bawah brand awareness, brand loyality, brand values dan brand culture.Tahapan tersebut seperti "ultimate destination of a brand" (economy.okezone.com). Dalam hal inikepercayaan yang tinggi telah ada pada suatumerek sehingga akan membentuk sebuah sikapdara rasa memiliki yang dalam antara keduanya.Sehingga semuanya akan terkemas dalam bentukeksklusivitas. Seperti Apple, MTV, Harley Davidsonyang telah memperoleh nilai ekslusif. Mere-kmerektersebut memiliki jutaan pengikut yang siapmemberi dukungan karena rasa loyalitas yangtinggi (K. Molekandella Boer, 2014).

Berdasarkan hal tersebut, peneliti terdorong untuk melakukan perancangan rebranding desain logo dari Abidaufa. Logo itu diharapkan dapat menjadi identitas yang khas, mewakili karakter, visi dan misi dari Abidaufa. Peneliti ingin memfokuskan redesain logo Abidaufa guna mendapatkan makna yang sesuai dengan karakter atau ciri khas dari Abidaufa.Bagaimana redesain brand identitas logo dari Abidaufa sebagai brand agar lebih dikenal dan diingat oleh pelanggan atau konsumen sebagai kerajinan yang berkualitas.Banyak yang belum mengenali produk dari Abidaufa. Hal ini sangat disayangkan sekali apabila potensi daerah dari Sumatera Utara tidak dikembangkan. Produk kerajinan Abidaufa memiliki kualitas yang sangat baik dan harga yang cukup terjangkau. Untuk memperoleh hasil perancangan logo dari Abidaufa yang komunikatif dan efektif, dan mampu mencapai tujuan, maka diperlukan sebuah metode yang baik untuk mewujudkannya.

Metode dalam redesain brandinglogo Abidaufa menggunakan metode observasi dan identifikasi data yang meliputi tahapan sepertipencatatan data primer dan sekunder dalam proses pra produksi, produksi, dan pasca produksi seperti pengumpulan data tentang seluruh aspek yang berkaitan denganAbidaufa, khususnya masalah produk apa saja yang dijual oleh Abidaufa. Hal ini meliputi nama produk, bahan-bahan untuk membuat produk, proses pembuatan, harga, cara dan model kemasan dan cara pemasarannya.Data sekunder berupa data yang diperoleh dari studi literatur yang dikumpulkan melalui studi pustaka terhadap sumber-sumber yang relevan mengenai perancangan logo dan data tentang pemanfaatan logo pada perusahaan. Selain dengan studi literature, data sekunder diperoleh melalui studi lapangan 
yakni untuk mendapatkan data perusahaan berbeda namun memiliki usaha yang sama.Dalam melakukan redesain branding logo Abidaufa, pengkarya juga menggunakan metode analisis $5 \mathrm{~W}+1 \mathrm{H}$, hal ini bertujuan agar logo yang dirancang dapat berkomunikasi dengan baik kepada audience melalui data yang telah didapat untuk dianalisis kembali.

\section{PEMBAHASAN}

Abidaufa bergerak dibidang produksi berbahan kulit hewan yang merupakanpotensi daerah Sumatera Utara yang beralamatkan Jl. Amal (Jl. Puskesmas) Medan-Binjai Km,7. Pemasaran yang dilakukan oleh Abidaufa yaitu melalui media onlinedan mengikuti acaraacara seperti PRSU (Pekan Raya Sumatera Utara) dan acara lainnya. Abidaufa belum memiliki toko untuk menjual produk yang mereka produksi, pelanggan dapat membeli dan memesan produk melalui media online dan datang langsung kerumah prodksi.Abidaufa merupakan salah satu pembisnis yang berawal dari bisnis Usaha Kecil Menengah (UKM).

Target perancangan adalah semua kalangan masyarakat, sebagaimana diuraikan berikut:

\section{Demografis}

$\begin{array}{ll}\text { Usia } & : \sim \text { tahun } \\ \text { Terdiri dari } & : \text { Anak-anak, Remaja, dewasa, orang tua } \\ \text { Jenis kelamin } & : \text { laki-laki dan perempuan }\end{array}$

\section{Geografis}

Lokasi sasaran yang dituju dalam perancangan ini adalah Kota Medan dan Luar Kota.

\section{Pisikografi}

Secara target perancangan ini diletakkan di rumah produksi itu sendiri, kemudian disebar memalui pembagian brosur dan pembuatan plank nama di pinggir jalan.

Konsep warna adalah penggunaan warna yang melambangkan kenyamanan dalam memproduksi produk yang diminati oleh konsumen, bertahan dalam memproduksi produk yang berkualitas tinggi dan dapat dipercaya dalammemperbaharui setiap produk yang diproduksikan serta bumi yang melambangkan adanya unsur tidak adanya pencemaran lingkungan untuk setiap produk yang diproduksi. Maka warna yang dipilih berdasarkan observasi dan analisis $5 \mathrm{~W}+1$ Hadalah coklat dan hitam.Pemilihan warna coklat mewakili kesan bumi, nyaman, bertahan dan dapat dipercaya.Pemilihan warna hitam mewakilikekuatan, professional, dan kemakmuran. Pengaplikasian warna tersebut diterapkan pada bagian logogram dan logotype Abidaufa yang di re-branding.

Menurut Utami, dkk., menyatakan bahwa:"pada konsep tipografi untuk logogram dan logotype perlu diperhatikan standartipografi antara lain legabilitas (huruf dapat terbaca dengan maksimal), readability (penggunaan huruf dengan memperhatikan hubungannya dengan huruf lain agar dapat terbaca), visibility (suatu huruf, kata, dan kalimat dalam suatu desain dapat terbacadalam jarak tertentu), dan clarity (kemampuan huruf dalam karya desain sehinggadapat dimengerti oleh pengamat yang dituju). Dari analisis tipografi, maka huruf yangmemiliki kesan dinamis, kreatif dan memiliki tingkat keterbacaan tinggi yakni fontsan serif"' (Utami, dkk, 2016:62). 
Hasil pengamatan yang telah dilakukan dengan metode analisis $5 \mathrm{~W}+1 \mathrm{H}$ menghasilkan data sebagai berikut :

Tabel 1. Data hasil analisis $\mathbf{5 W}+\mathbf{1 H}$

(Sumber : Ivo Ramadhani, 2017)

\begin{tabular}{|l|l|}
\hline What & $\begin{array}{l}\text { : Redesain branding Logo } \\
\text { Abidaufa }\end{array}$ \\
\hline Where & $\begin{array}{l}\text { : Jl. Amal (Jl. Puskesmas) Medan- } \\
\text { Binjai Km,7 }\end{array}$ \\
\hline When & : Saat ini, \\
\hline Who & $\begin{array}{l}\text { : Pemilik, karyawan dan pelanggan } \\
\text { Abidaufa, }\end{array}$ \\
\hline Why & $\begin{array}{l}\text { : Belum adanya Identitas Desain } \\
\text { Logo Abidaufa, }\end{array}$ \\
\hline How & $\begin{array}{l}\text { : Meredesain logo kemudian akan } \\
\text { diaplikasikan kebeberapa media. }\end{array}$ \\
\hline
\end{tabular}

Hasil data yang telah diperoleh kemudian dirangkum dari hasil analisis digunakan sebagai arahan dalammembuat desain logo yang efektif. Dengan konsepwarna, tipografi, dan jenis komposisi yangmemberikan kesan kenyamanan,bertahan, bumi,dandapat dipercaya. Jenis font yang digunakan adalah "Backslash" yangmerupakan jenis dari font san serif. Font ini memiliki kesan dinamis, kreatifdan memiliki tingkat keterbacaan tinggi sehingga sesuai dengan karakter dariAbidaufa. Pada warna yangdipilih adalah coklat dan hitam. Pemilihan warna coklat mewakilikesan bumi, nyaman,bertahan dan dapat dipercaya.Pemilihan warna hitam mewakilikekuatan, professional, dan kemakmuran. Pengaplikasian warna tersebut diterapkan pada bagianlogogramdan logotype Abidaufa yang akan diredesain.

a. Logo Abidaufa

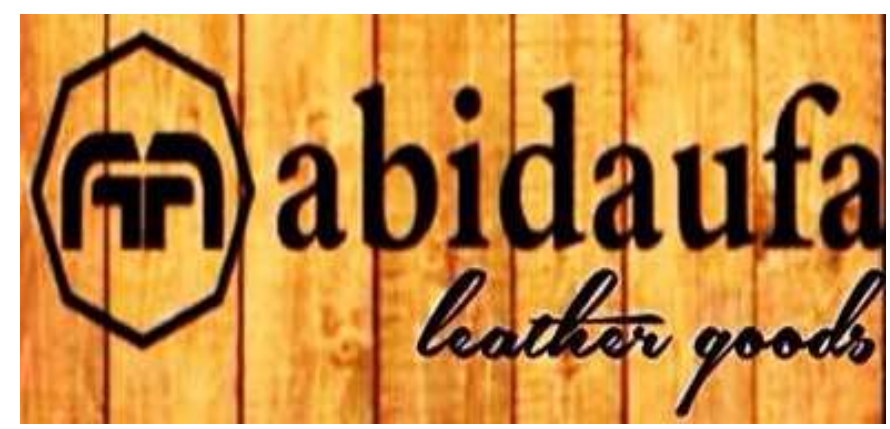

Gambar 2. Logo Abidaufa

(Sumber : Ivo Ramadhani, 2017)

Berdasarkan konsep yang sudah dirumuskan, maka di antara alternatif desain akan dipilih dan dikembangkan sehingga menghasilkan sebuah redesain dari akhir yang digunakan oleh Abidaufa. 
Layout yang digunakan pada karya ini menerapkan prinsip keseimbangan yang ada agar penempatan objek-objek didalamnya tetap terkesan dinamis dan tidak brantakan. Pengaturan tata letak konten agar target audience mudah menangkap pesan yang disampaikan. Keseimbangan tidak hanya memperhatikan ruang yang berisi konten tetapi juga memperhatikan ruang kosong.

b. Pembuatan Sketsa Logo

1. Alternatif desain pertama

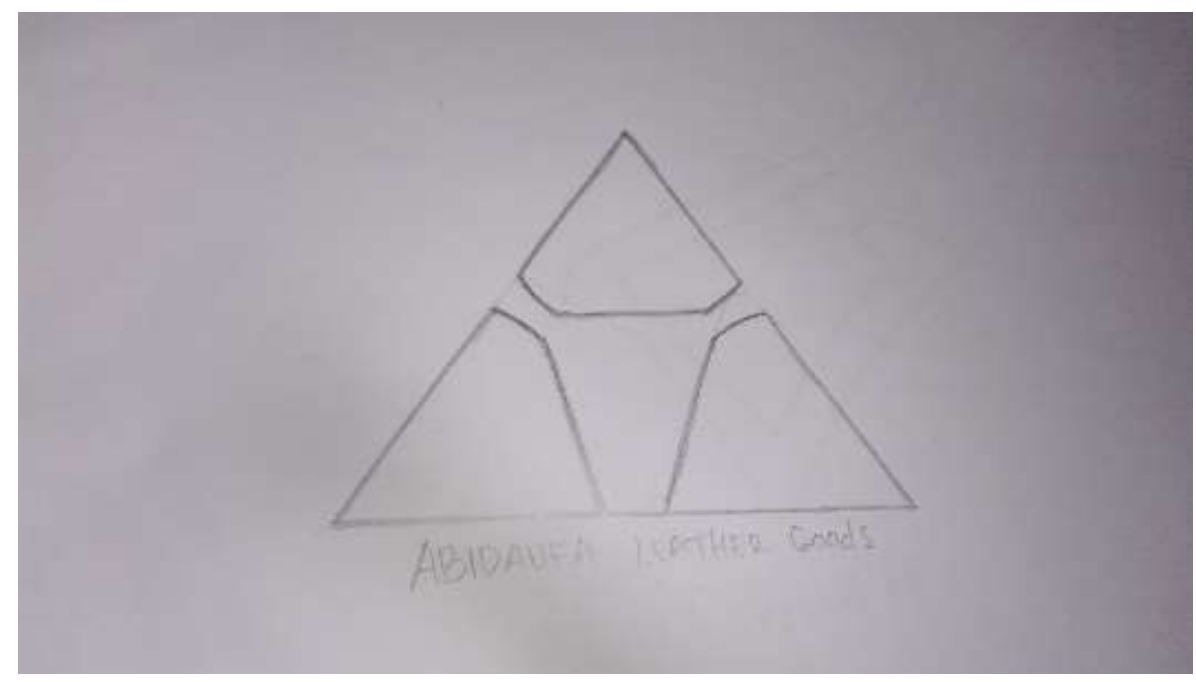

Gambar 3. Sketsa Logo Abidaufa

(Sumber : Ivo Ramadhani, 2017)

2. Alternatif desain kedua

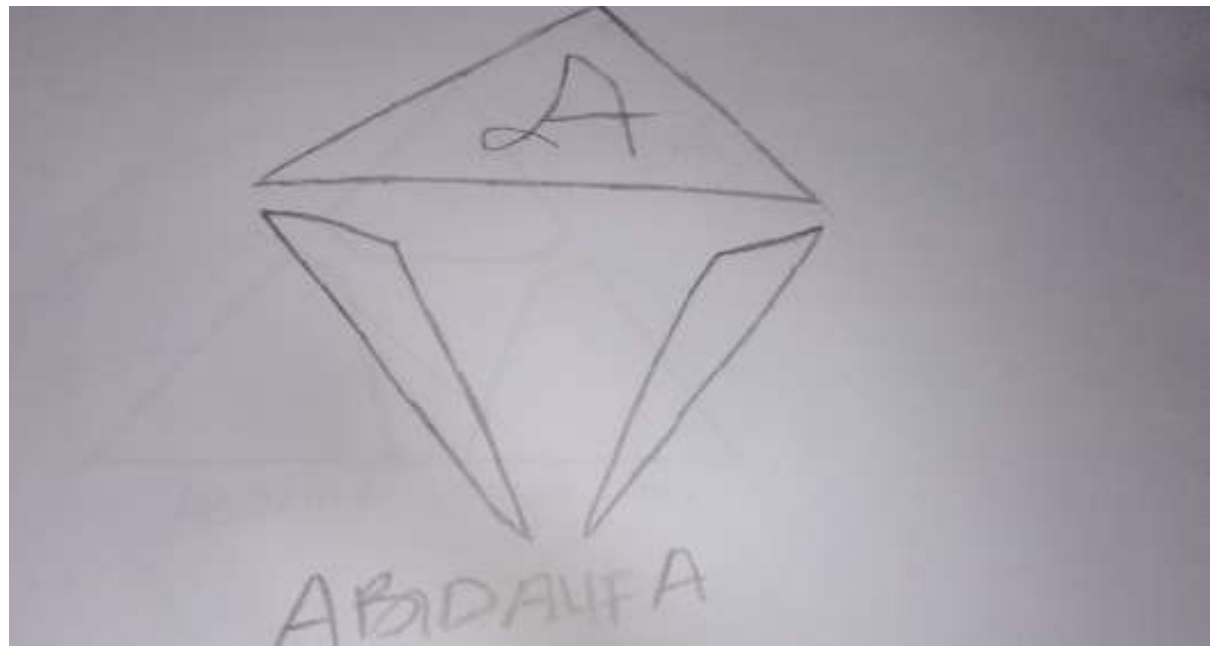

Gambar 4. Sketsa Logo Abidaufa (Sumber : Ivo Ramadhani, 2017) 
3. Alternatif desain ketiga

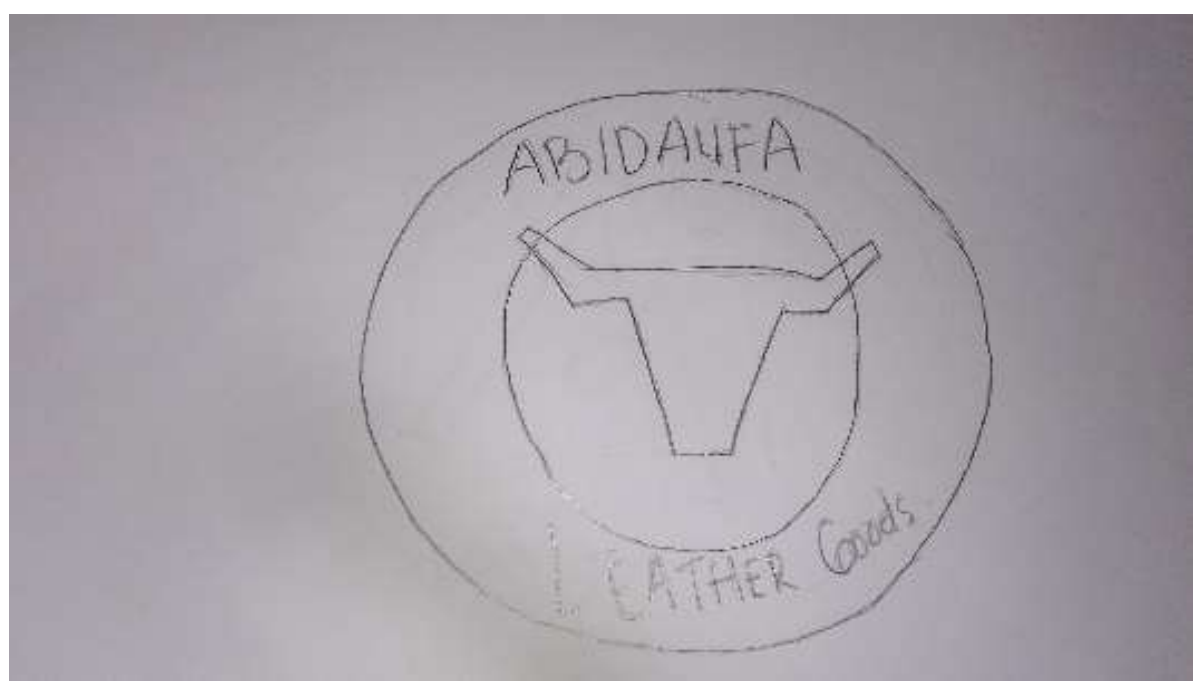

Gambar 5. Sketsa Logo Abidaufa

(Sumber : Ivo Ramadhani, 2017)

4. Alternatif desain keempat

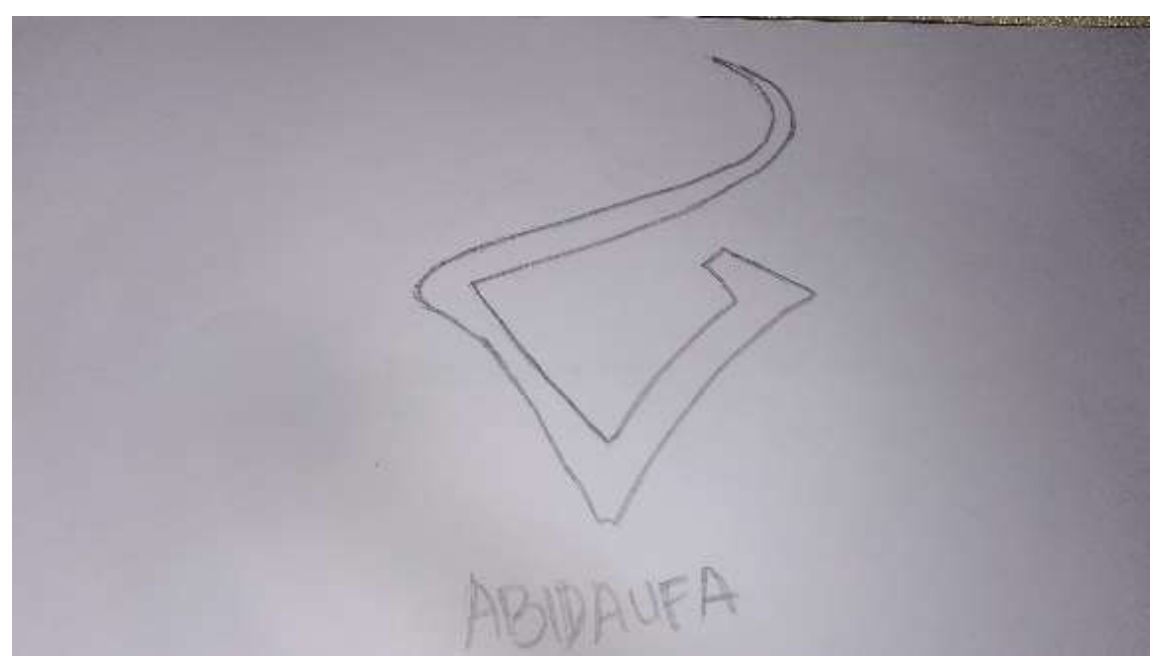

Gambar 6. Sketsa Logo Abidaufa

(Sumber : Ivo Ramadhani, 2017)

c. Alternatif Tipografi

Alternatif tipografi merupakan beberapa pilihan huruf yang akan digunakan dalam perancangan. Terdapat 4 alternatif jenis pilihan huruf pada rancangan redesain logo Abidaufa. Setelah melakukan pemilihan, maka akan terpilih 1 alternatif jenis huruf. Berikut table alternatif pemilihan huruf yang akan digunakan. 
Table 2. Alternatif pilihan huruf

(Sumber : Ivo Ramadhani, 2017)

\begin{tabular}{|l|c|c|}
\hline BRANDNAME & $\begin{array}{c}\text { JENIS } \\
\text { HURUF }\end{array}$ & STATUS \\
\hline ABIDAUFA & Algerian & $\mathrm{X}$ \\
\hline ABIDAUFA & $\begin{array}{c}\text { Cooper } \\
\text { Black }\end{array}$ & $\mathrm{X}$ \\
\hline ABIDAUFA & $\begin{array}{c}\text { Segoe } \\
\text { Script }\end{array}$ & $\mathrm{X}$ \\
\hline ABIDAUFA & Backslash & $\checkmark$ \\
\hline
\end{tabular}

Jenis tipografi yang terpilih adalah "blackslash" karena memiliki kesan huruf yang menyerupai karakter dari olahan produk Abidaufa. Huruf blackslah akan didigunakan sebagai logotype pada logo Abidaufa.

\section{d. Pemilihan Desain Final}

Melalui beberapa alternatif sketsa logo yang telah didesain, maka desain logo yang menjadi pilihan dalam redesain branding logo Abidaufa yaitu sketsa gambar.5. Logo tersebut terpilih karena memiliki keunikan yang mewakili secara utuh konsep logo pada rancangan sebelumnya. Bentuk yang unik dan menggunakan warna yang tepat dan tipografi yang sesuai dengan karakter Abidaufa. Berikut desain final Abidaufa yang telah divisualkan.

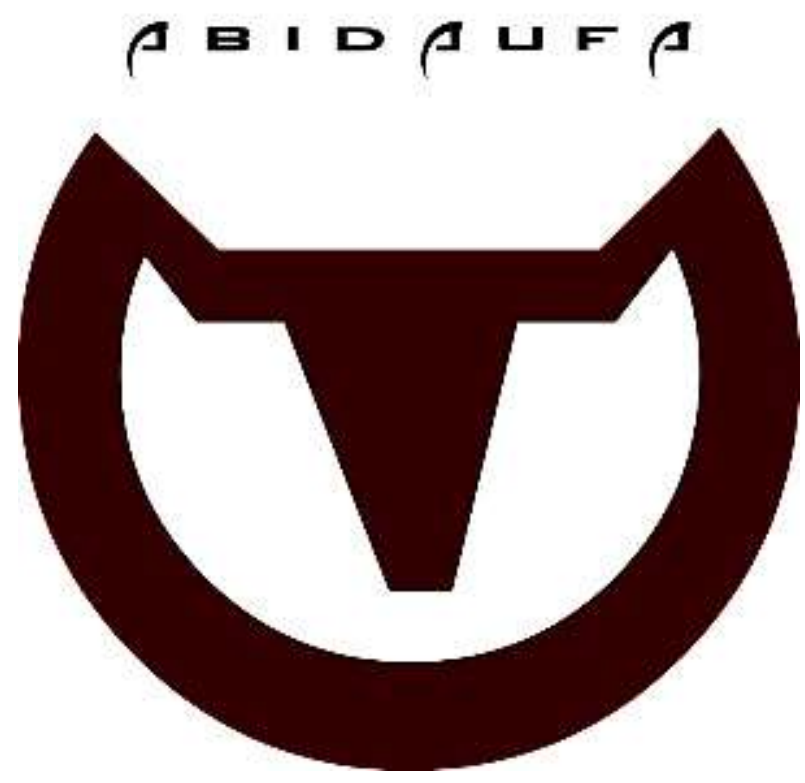

Gambar 7. Desain final logo Abidaufa

(Sumber : Ivo Ramadhani, 2017) 
1. Penjelasan Makna Logo

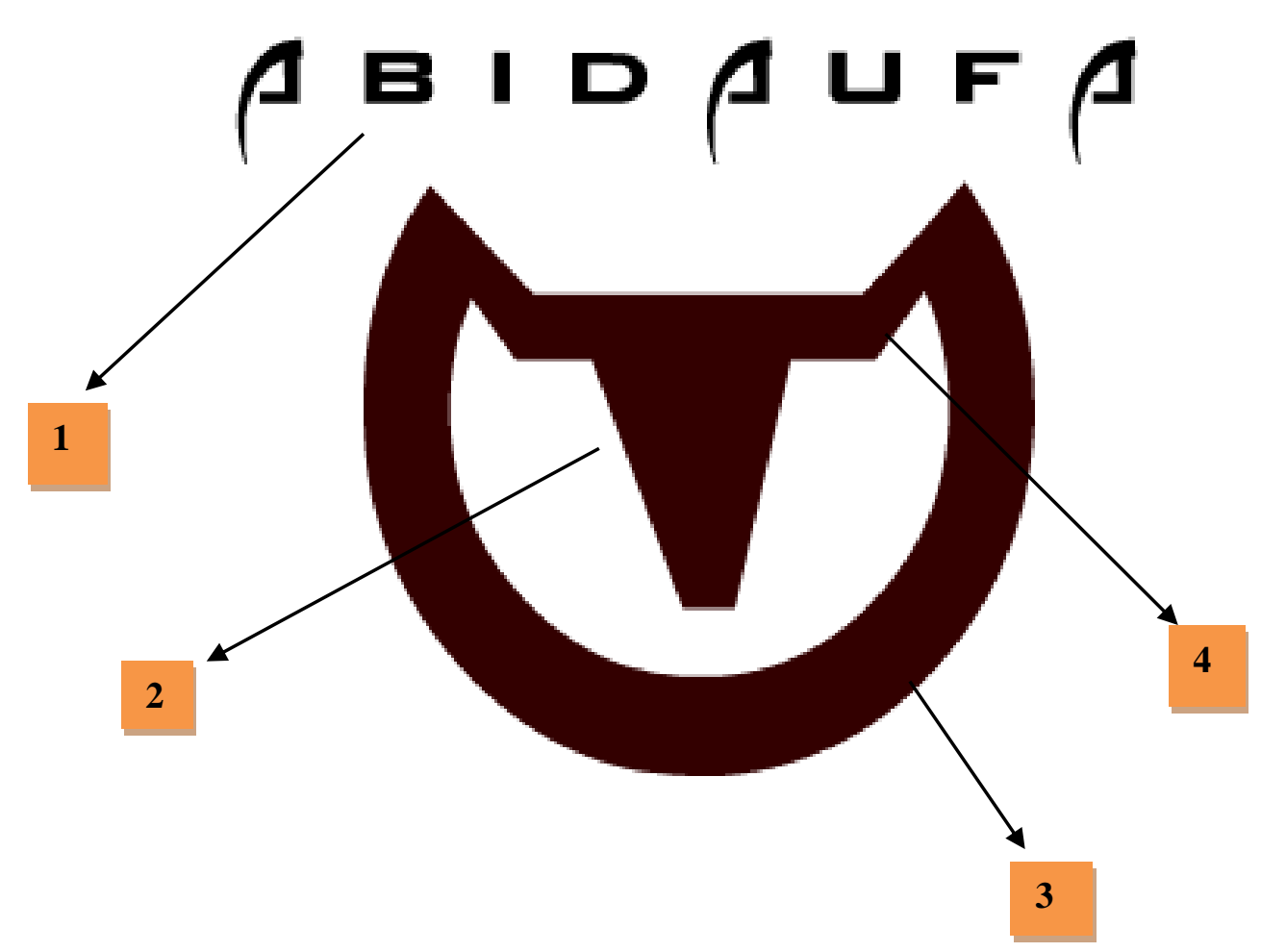

Gambar 8. Penjelasan makna logo

(Sumber : Ivo Ramadhani, 2017)

Adapun penjelasan makna logo sebagai berikut :

1. Logotype Abidaufa mengunakan typografi blackslah, secara psikologi juga mengartikan bahwa olahan produk Abidaufa adalah perbahan kulit sapi.

2. Karakter nama Abidaufa merupakan awalan nama dari pemilik Abidaufa yaitu huruf "A".

3. Lingkaran pada logo Abidaufa menyerupai sebuah stir mobil yang menggambarkan bahwasannya perjalanan panjang dari sebuah usaha yang mesti ditempuh dan dapat menjalankan usaha dengan satu tujuan berdasarkan misi dan visidan mempererat tali persahabatan dan persaudaraan Abidaufa.

4. Bentuk kepala sapi yang terdapat pada logo Abidaufa merupakan karakter olahan produk yang paling utama di produksi yaitu kulit sapi.

5. Warna coklat menggambarkan olahan produk kulit yang pada umumnya yaitu berwarna coklat, dan warna coklat dapat diartikan mewakili kesan bumi, nyaman, bertahan dan dapat dipercaya. Warna hitam mewakili kekuatan, professional, dan kemakmuran.

Pada warna yangdipilih adalah coklat dan hitam. Pemilihan warna coklat mewakili kesan bumi, nyaman, bertahan dan dapat dipercaya.Pemilihan warna hitam mewakilikekuatan, professional, dan kemakmuran. Pengaplikasian warna tersebut diterapkan pada bagian logogram dan logotype Abidaufa yang akan dire-branding. 
Berdasarkan desain yang sudah dipilih, kemudian dikembangkan dan diaplikasikan ke dalam desain media yang lain. Pengaplikasian dilakukan untuk melakukan promosi terhadap produk yang akan dipasarkan, sehingga banyak konsumen yang tertarik ataupun mengenali produk dari Abidaufa.

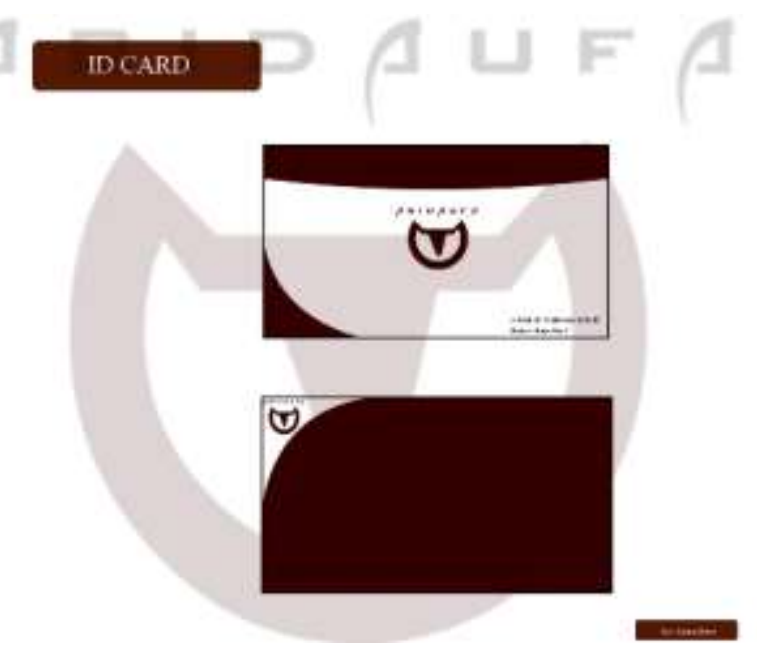

Gambar 9. Desain id card depan belakang (Sumber : Ivo Ramadhani, 2017)

Id card digunakan untuk media promosi dengan memberikan informasi tentang pemilik Abidaufa berupa contack person.

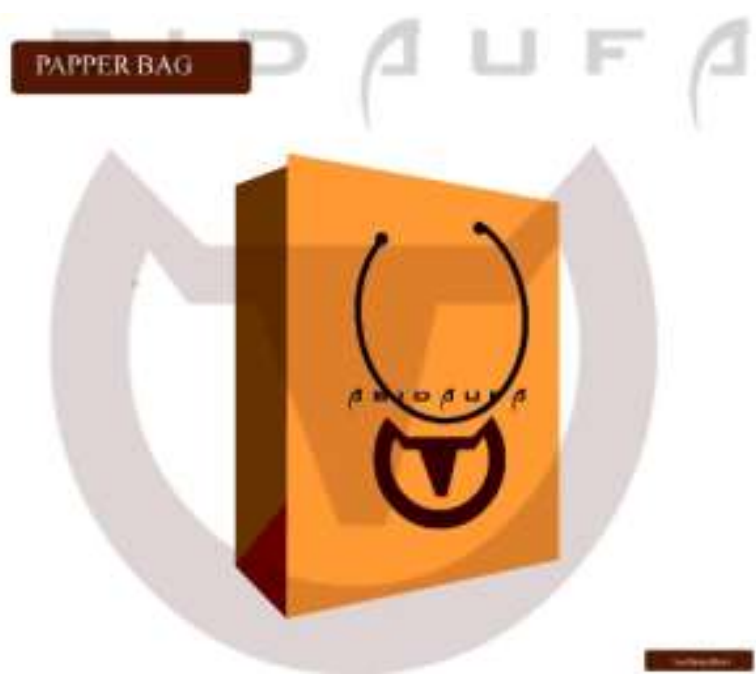

Gambar 10. Desain papper bag

(Sumber : Ivo Ramadhani, 2017)

Papper bag merupakan media wadah / tempat produk yang dibeli oleh pelanggan Abidaufa. 


\section{BONFAKTUR}

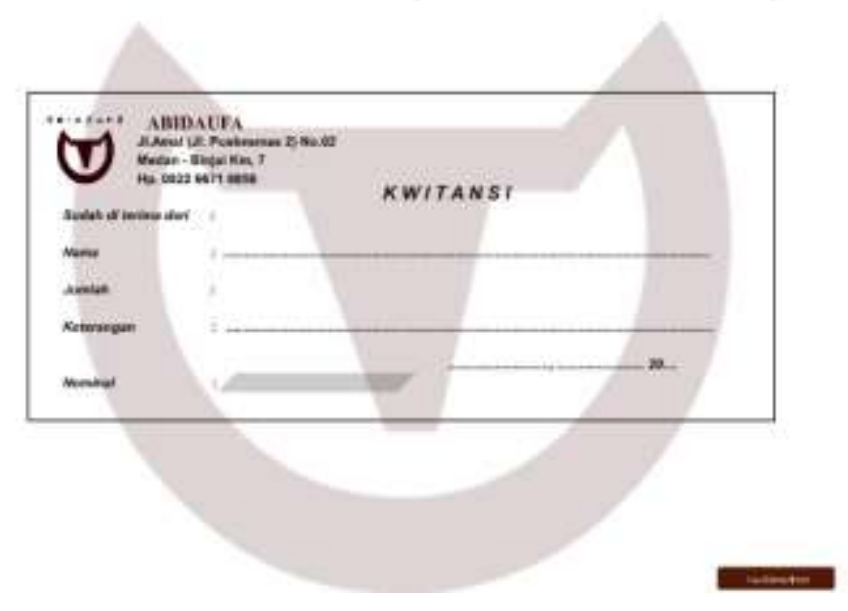

Gambar 11. Desain bon faktur

(Sumber : Ivo Ramadhani, 2017)

Bon faktur merupakan media yang digunakan pada saat transaksi proses jual beli yang dilakukan Abidaufa kepada pelanggan sebagai bukti.

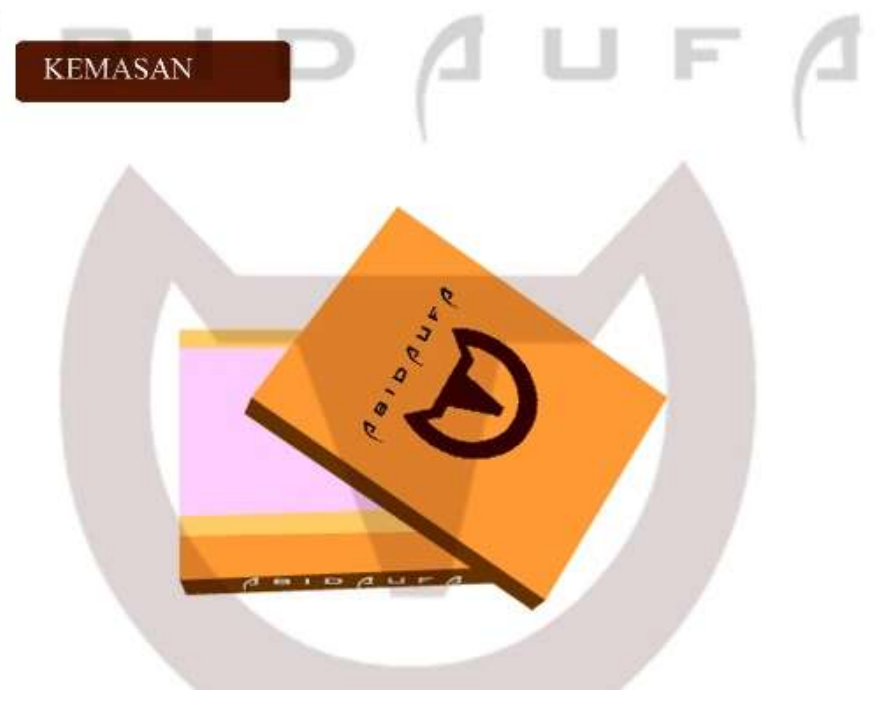

Gambar 12. Desain kemasan dompet

(Sumber : Ivo Ramadhani, 2017)

Kemasan merupakan media tempat yang digunakan untuk kemasan dari produk olahan Abidaufa berupa produk dompet. 


\section{KESIMPULAN}

Desain dibuat dengan minimalis dan disesuaikan dengan target sasaran klien, agarlogo dengan mudah dikenali dan diingat oleh klien. Dalam suatu desain perlu diperhatikan dalam pemilihan dan penggunaan garis,bentuk, warna, tekstur, dan lainlain.Penggunaan logotype dan logogram didesain dengan komposisi yang proporsional dan dapat diaplikasikan ke semua media dan background.Pemilihan warna coklat mewakili kesan bumi, nyaman, bertahan dan dapat dipercaya.Pemilihan warna hitam mewakilikekuatan, professional, dan kemakmuran. Pengaplikasian warna tersebut diterapkan pada bagian logogram dan logotype Abidaufa yang akan diredesain.Jenis tipografi yang terpilih adalah "blackslash" karena memiliki kesan huruf yang menyerupai karakter dari olahan produk Abidaufa. Huruf blackslah akan didigunakan sebagai logotype pada logo Abidaufa.

\section{DAFTAR PUSTAKA}

\section{Jurnal :}

[1] D.W. Utami, Athika, Lukman Hakim. 2016. Perancangan Desain Logo Lbh Sandhi Wafa \& Partners Counselor \& Attorneys At Law Jurusan Desain Komunikasi Visual, Universitas Nahdlatul Ulama Sidoarjo, Sidoarjo.

\section{Artikel ilmiah:}

[2] Iskandar, Riki. (2016). Rancangan Brand Indentity Songket Silungkang Kota Sawahlunto. Institut Seni Indonesia Padangpanjang. Tesis

\section{Jurnal :}

[3] Kurniawan, Denny. 2008. Perancangan Logo Dan Maskot Untuk Mendukung Promosi Wisata Kuliner Malam Warung Tradisional Di Surabaya Jurusan Desain Komunikasi Visual, Fakultas Seni dan Desain. Surabaya:Universitas Kristen Petra.

[4] Lip, Evelyn. 1996. Desain dan Feng Shui. Jakarta: PT Elex Media Komputindo.

\section{Buku :}

[5] Kusrianto, Adi. (2007). Pengantar Desain Komunikasi Visual. Yogyakarta: Andi Offset

\section{Jurnal :}

[6] R.W. Ratranto, F.X, Agus Rahmat, Yanti Setiani. 2012. Simbolisasi Logo Maicih For Ichiers With Love Jurusan Ilmu Hubungan Masyarakat Fakultas Ilmu Komunikasi, Universitas Padjadjaran.

[6] Suwardikun, W. Didit. 2002. Perubahan Logo Perusahaan, Sebuah Analisis Visual (Studi Kasus : PT. Astra Internasional, Garuda Indonesia, Unocal 76). Tesis, FakultasSeniRupa dan Desain, Desain Komunikasi Visual, InstitutTeknologi Bandung, Bandung. 